\title{
Fat-containing liver lesions: a pictorial review
}

Lesões hepáticas que contêm gordura: ensaio iconográfico

Daniella Braz Parente ${ }^{1}$, Jaime Araújo Oliveira Neto ${ }^{2}$, Antonio Luis Eiras de Araújo ${ }^{3}$, Rosana Souza Rodrigues ${ }^{1}$, Renata Mello Perez ${ }^{1}$, Edson Marchiori ${ }^{4}$

Parente DB, Oliveira Neto JA, Eiras-Araújo AL, Rodrigues RS, Perez RM, Marchiori E. Fat-containing liver lesions: a pictorial essay. Radiol Bras. 2018 Jan/Fev;51(1):52-57.

Abstract The aim of this pictorial essay is to review the spectrum of fat-containing liver lesions and their characterisation on magnetic resonance imaging with focus on the radiological features that aid in the differential diagnoses. Fat-containing liver lesions comprise a heterogeneous group of tumours with variable imaging findings. Magnetic resonance imaging clearly displays the micro- and macroscopic fat components of the lesions and other characteristic features that are helpful tools to make the differential diagnosis. Keywords: Fatty liver/diagnostic imaging; Liver neoplasms/diagnostic imaging; Magnetic resonance imaging.

Resumo 0 objetivo deste ensaio é rever o espectro de lesões hepáticas que contêm gordura e caracterizar seus aspectos de imagem na ressonância magnética, com foco nas características radiológicas que auxiliam no diagnóstico diferencial. As lesões hepáticas que contêm gordura compreendem um grupo heterogêneo de tumores com aspectos de imagem variáveis. A ressonância magnética exibe claramente os componentes de gordura microscópica e macroscópica das lesões e outras características que são úteis para fazer diagnósticos diferenciais.

Unitermos: Fígado gorduroso/diagnóstico por imagem; Neoplasias hepáticas/diagnóstico por imagem; Ressonância magnética.

\section{INTRODUCTION}

The increasing use of imaging examinations for abdominal evaluation and recent technical advances in radiology have led to an increase in the number of liver lesions detected. The evaluation of the liver by imaging methods has been the subject of a series of recent publications in the radiology literature of Brazil ${ }^{(1-10)}$. Most liver lesions are benign and can be diagnosed on the basis of their imaging characteristics ${ }^{(11)}$.

This pictorial essay reviews the characteristics of fatcontaining liver lesions on magnetic resonance imaging (MRI), with or without gradient-recalled echo (GRE) sequences. We highlight the patterns of fat components that aid in the various differential diagnoses.

\section{LIVER LESIONS CONTAINING MACROSCOPIC FAT}

\section{Angiomyolipoma}

Angiomyolipomas are rare benign mesenchymal tumours. These lesions exhibit variable signal intensity on MRI because they contain different amounts of fat,

Study conducted at Universidade Federal do Rio de Janeiro (UFRJ) and at D'Or Institute for Research and Education, Rio de Janeiro RJ, Brazil.

1. MD, PhD, Universidade Federal do Rio de Janeiro (UFRJ) and D'Or Institute for Research and Education, Rio de Janeiro RJ, Brazil.

2. MD, D'Or Institute for Research and Education, Rio de Janeiro, RJ, Brazil.

3. MD, Universidade Federal do Rio de Janeiro (UFRJ) and D'Or Institute for Research and Education, Rio de Janeiro RJ, Brazil. Brazil. smooth muscle and blood vessels. Characteristic features include the presence of fat and prominent central vessels. Fat-rich angiomyolipomas show high signal intensity on T1-weighted images and a significant signal drop on fatsaturated images. Their enhancement occurs later than does that of hepatocellular carcinomas. Unlike the fatty components of hepatocellular carcinomas, those of angiomyolipomas are well vascularised and enhance early ${ }^{(12-14)}$, as depicted in Figure 1. The differential diagnosis of an angiomyolipoma typically includes lipomas, hepatocellular adenomas, hepatocellular carcinomas, sarcomas and metastatic neoplasias $^{(13)}$.

\section{Lipoma}

Hepatic lipomas are extremely rare. They consist of mature adipose tissue and appear as homogenous fatty lesions on MRI. Hepatic lipomas show high signal intensity on T1-weighted images and a significant signal drop on fat-saturated images, without enhancement ${ }^{(12,14)}$, as shown in Figure 1.

\section{Pericaval fat}

The localised collection of fat posterior to the inferior vena cava is a normal variant that mimics a fat-containing lesion on cross-sectional images. Pericaval fat collections are rare incidental findings that are frequently associated

Mailing address: Dra. Daniella Braz Parente. Rua General Garzon, 100, ap. 1002, Lagoa. Rio de Janeiro, RJ, Brazil, 22470-010. E-mail: daniella.parente@gmail.com.

Received August 8, 2016. Accepted after revision August 19, 2016. 
gure 1. Hepatic lipomatous lesion A: Axial in-phase T1-weighted GRE image shows a small hyperintense esion (arrow). B: Axial out-of-phase T1-weighted GRE sequence shows peripheral signal loss (arrow). This is a lipomatous lesion and can represent either a lipoma or an angiomyolipoma.

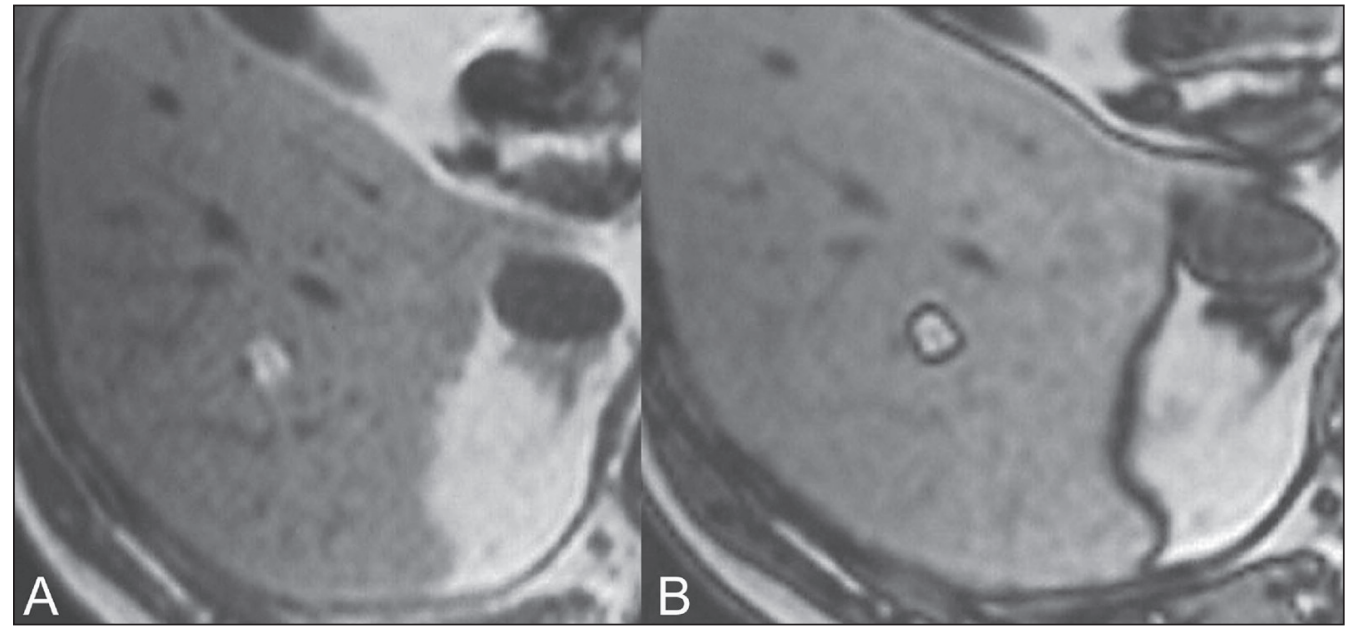

with chronic liver disease. Their differential diagnosis includes inferior vena cava thrombi and tumours ${ }^{(14,15)}$.

\section{Pseudolipoma of Glisson's capsule}

Pseudolipomas of Glisson's capsule are encapsulated lesions that contain degenerated fat. Serosal metastases and fibrosing subcapsular necrotic nodules are considered in the differential diagnosis. On MRI, these pseudolipomas appear as well-circumscribed nodules on the liver capsule, with fatty or soft-tissue centres ${ }^{(14,16)}$, as can be seen in Figure 2.

\section{Liposarcoma}

Liposarcomas are rare mesenchymal malignant tumours that account for $15 \%$ of all sarcomas. Primary or metastatic liver liposarcomas are extremely rare. They appear as fatty heterogeneous, lobulated, infiltrating masses with areas of haemorrhage and necrosis ${ }^{(12,14)}$.

\section{Metastases}

Metastases have the same histology as primary neoplasms. Fat-containing primary tumours such as teratomas, liposarcomas, Wilms' tumours and renal cell carcinomas can metastasise fat-containing lesions to the liver ${ }^{(12,14)}$, as depicted in Figure 3.

\section{Hepatic teratoma}

Hepatic teratomas are benign, heterogeneous, encapsulated tumours formed by parts of all three germ cell layers. These lesions are frequently cystic and contain fat, hair, protein-rich debris and calcifications. On MRI, hepatic teratomas are well-circumscribed and heterogeneous, and they can be recognised by the identification of fat, fluid and calcifications. Most hepatic teratomas represent intraperitoneal or retroperitoneal teratomas that have spread to the liver ${ }^{(14)}$.

\section{LIVER LESIONS CONTAINING MICROSCOPIC FAT}

\section{Focal hepatic steatosis}

Focal hepatic steatosis can appear as a nodule, which leads to the consideration of other focal lesions in the differential diagnosis. Focal fat deposition occurs preferentially in the posterior aspect of segment IV, adjacent to the

Figure 2. Pseudolipoma of Glisson's capsule. A: Axial in-phase T1 weighted GRE sequence shows a small subcapsular hyperintense lesion (arrow). B: Axial out-of-phase T1-weighted GRE image shows peripheral signal loss (arrow).

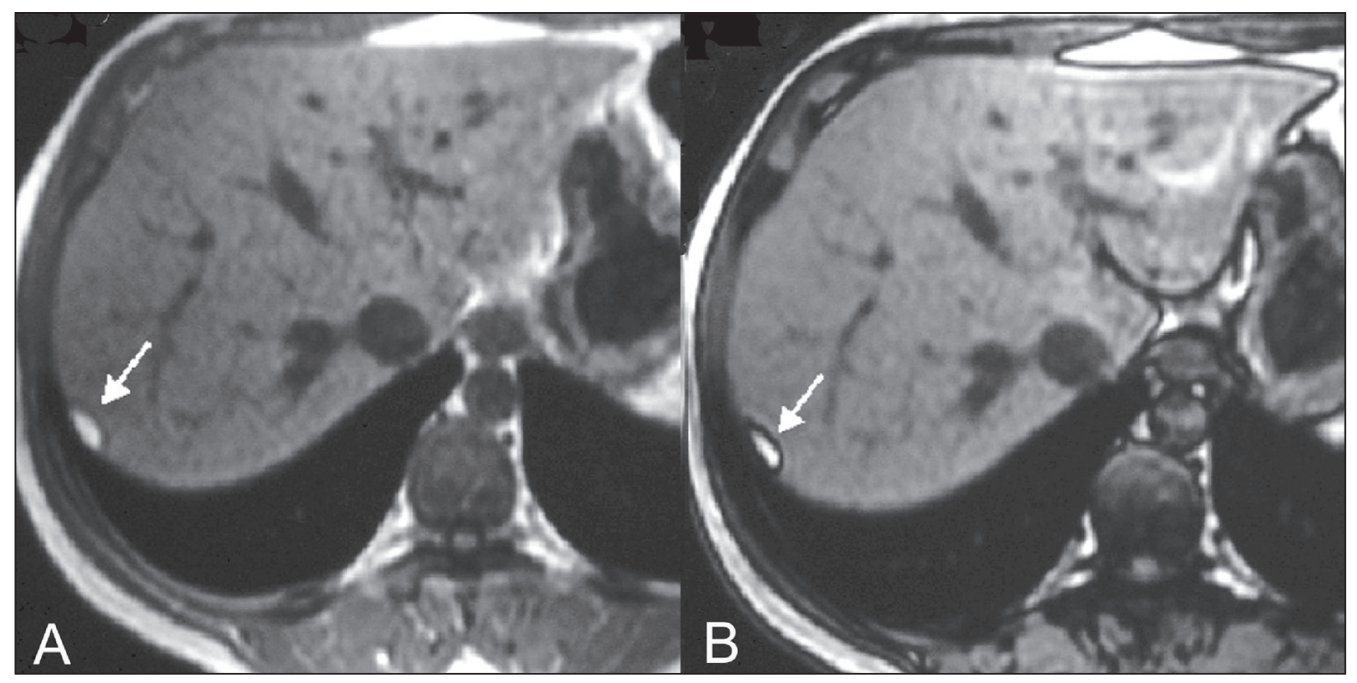




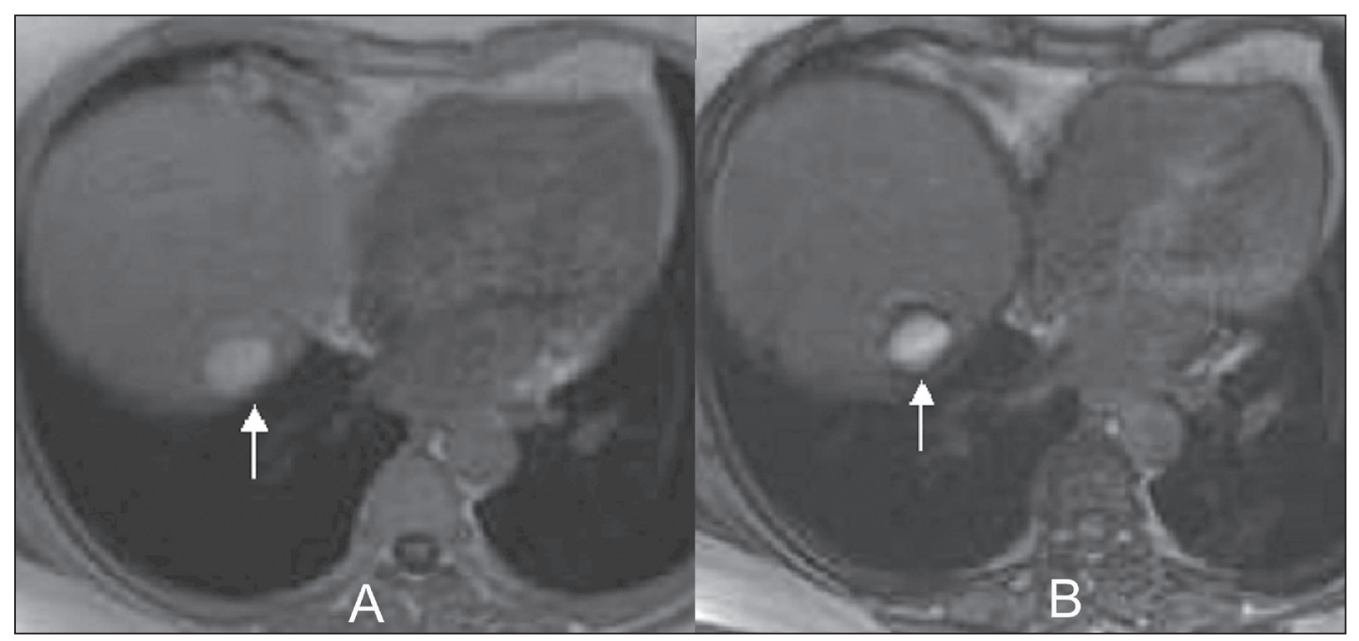

Figure 3. Teratocarcinoma metastasis from an ovarian source with peritoneal dissemination. A: Axial in-phase T1-weighted GRE image shows a small hyperintense lesion on the hepatic dome (arrow). B: Axia out-of-phase T1-weighted GRE sequence shows peripheral signal loss (arrow). Mild diffuse decrease in the signal intensity of the liver, due to steatosis is also observed. falciform ligament and along the gallbladder fossa. The lesions are characterised by geographic borders and lack a mass effect; vessels and biliary ducts traverse the area without deviation. On in-phase images, they are iso- to hyperintense with a signal drop on out-of-phase images and enhancement equal to that of the surrounding liver.
As illustrated in Figures 4 and 5, multifocal steatoses must be differentiated from metastatic diseases ${ }^{(12,14)}$.

\section{Hepatic adenoma}

Hepatic adenomas are benign, encapsulated lesions that occur in healthy young women and are strongly related
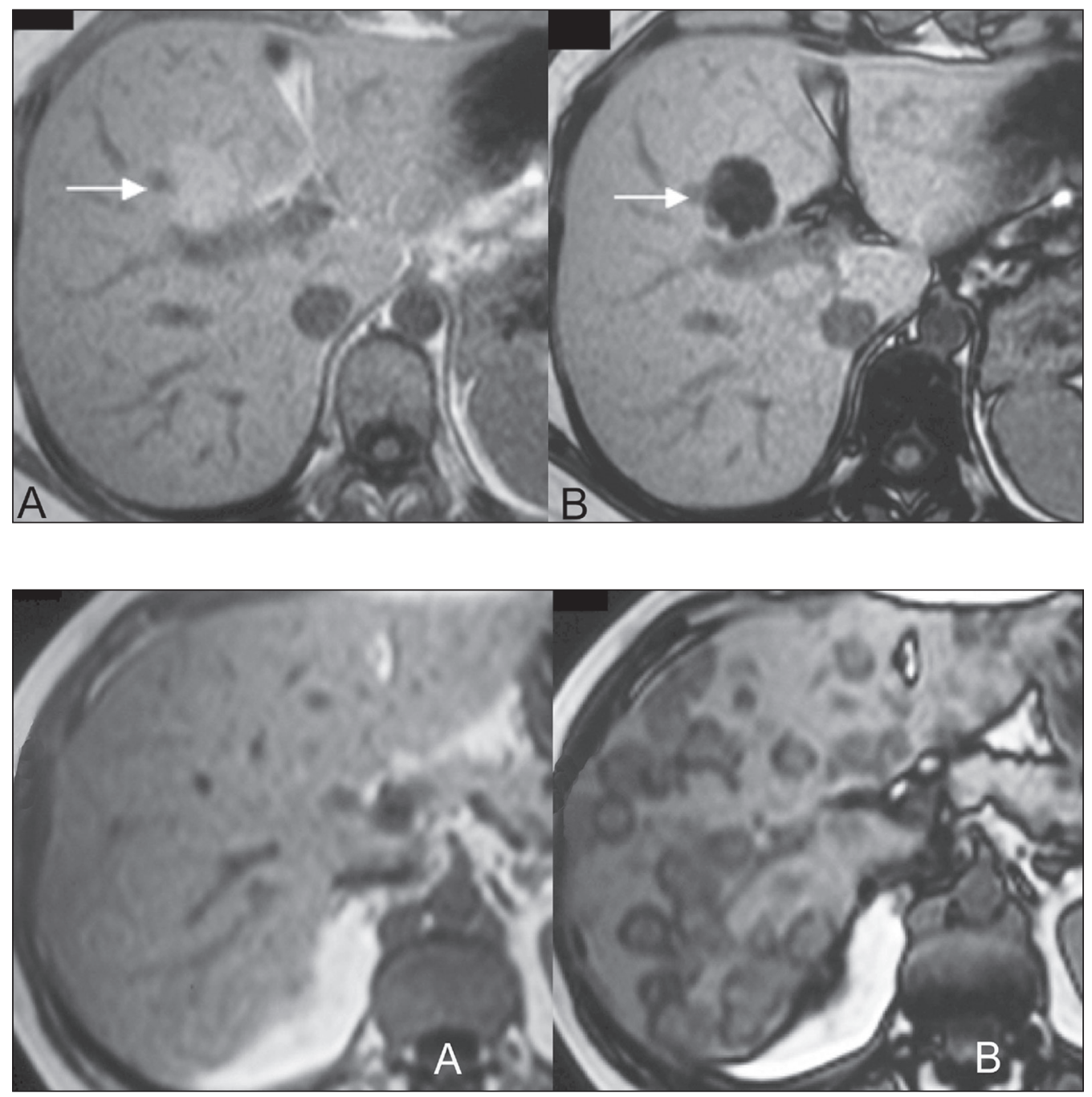

Figure 4. Focal hepatic steatosis. A: Axial in-phase T1-weighted MRI scan shows a hyperintense lesion in the posterior region of segment IV (arrow). B: Axial out-of-phase T1 weighted image shows uniform decrease in the signal intensity of the lesion (arrow).

Figure 5. Multinodular hepatic steatosis. A: Axial in-phase T1-weighted GRE sequence shows multiple slightly hyperintense foci diffusely distributed in the liver. B: Axial out-ofphase T1-weighted GRE sequence shows signal loss in the foci. 
to the use of oral contraceptives. Anabolic steroid use and glycogen storage disease are also risk factors. Adenomas can bleed or rupture and have a small risk of malignant transformation. Large or multiple lesions, subcapsular location and pregnancy increase the risk of bleeding. Hepatic adenomas are well-circumscribed lesions. They are typically slightly hyperintense on T2-weighted images and iso- to hyperintense on T1-weighted images, with arterial enhancement and washout. Out-of-phase images show signal loss in the fatty component. The main differential diagnosis is focal nodular hyperplasia ${ }^{(11,12,14)}$.

\section{Focal nodular hyperplasia}

Focal nodular hyperplasias are the second most common benign liver lesions. They occur most commonly in healthy young women, although their relationship with oral contraceptive use is not as well-established as is that of adenomas. The presence of fat is uncommon in focal nodular hyperplasias and usually associated with hepatic steatosis. Focal nodular hyperplasias appear as iso- to hypointense nodules on T1-weighted images and iso- to hyperintense nodules on T2-weighted images, similar to the surrounding parenchyma. The nodules enhance homogeneously in the arterial phase and show enhancement similar to the surrounding liver in the portal phase. A central scar, composed of deformed biliary ducts, blood vessels and inflammatory cells, is characteristically present. The scar is hyperintense on T2-weighted images and hypointense on T1-weighted images (Figure 6). In addition, the scar does not enhance in the arterial phase but does enhance in the equilibrium phase. The central scar can be absent, especially on small lesions. In such cases, retention of hepatobiliary contrast agents can be diagnos$\operatorname{tic}^{(11,12,14,17)}$.

\section{Steatotic regenerative nodules}

Regenerative nodules are the most common nodules in cirrhotic livers. They are usually small, numerous and diffusely distributed throughout the parenchyma. Such nodules can contain fat and show high signal intensity on in-phase images and signal loss on out-of-phase im$\operatorname{ages}^{(18)}$, as illustrated in Figure 7.

\section{Hepatocellular carcinomas}

Hepatocellular carcinomas are the most common malignant lesions in cirrhotic livers. They usually show variable signal intensity on T1-weighted images and are hyperintense on T2-weighted images (Figure 8). Hepatocellular carcinomas enhance in the arterial phase and have washout in the delayed phases. Pseudocapsule enhancement is characteristic in the equilibrium phase. The fatty components of hepatocellular carcinomas are visible on MRI as a signal drop in fat-suppressed techniques and do not enhance as much as the rest of the lesion $^{(11,12,14,18)}$.

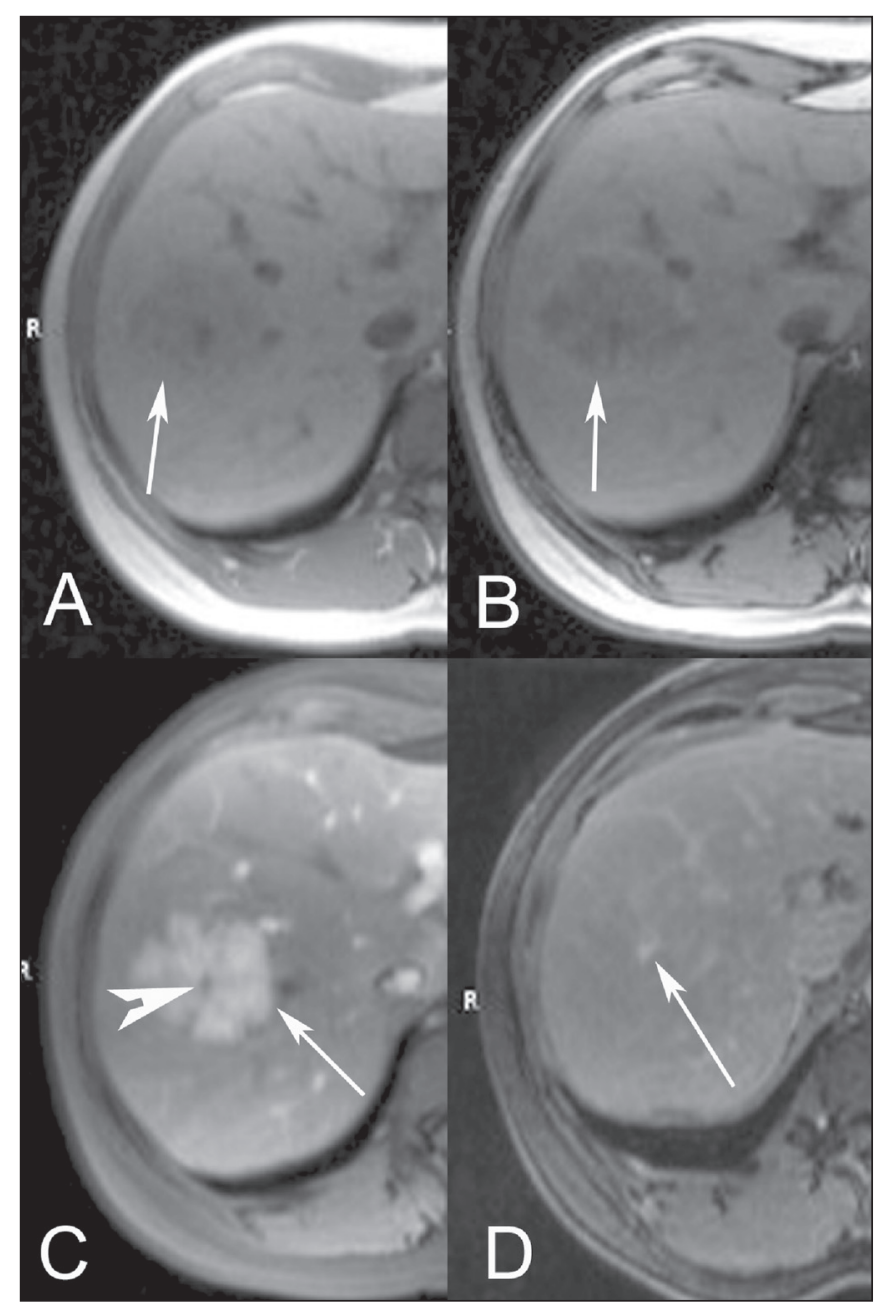

Figure 6. Focal nodular hyperplasia. A: Axial in-phase T1-weighted GRE sequence shows a hypointense lesion (arrow). B: Axial out-of-phase T1-weighted GRE sequence shows diffuse signal loss within the lesion (arrow). C: Axial gadolinium-enhanced T1-weighted GRE arterial phase image shows intense homogeneous enhancement of the entire lesion (arrow), except for the central scar (arrowhead). D: Axial gadolinium-enhanced T1-weighted GRE equilibrium phase image shows that the lesion has become isointense relative to the surrounding parenchyma, and that the central scar has enhanced (arrow).

\section{CONCLUSION}

Fat-containing liver lesions constitute a heterogeneous group of tumours. Careful evaluation of the clinical history, together with the MRI findings, will facilitate the differential diagnoses of these lesions.

\section{REFERENCES}

1. Siqueira GRS, Guimarães MD, Franco LFS, et al. Exophytic hepatocellular carcinoma, simulating a mesenchymal tumor, in a noncirrhotic liver. Radiol Bras. 2017;50:62-6.

2. Staziaki PV, Teixeira BCA, Pedrazzani BM, et al. Hepatoblastoma with solid and multicystic aspect mimicking a mesenchymal hamartoma: imaging and anatomopathologic findings. Radiol Bras. 2017;50:68.

3. Ramalho M, Matos AP, AlObaidy M, et al. Magnetic resonance imaging of the cirrhotic liver: diagnosis of hepatocellular carcinoma and evaluation of response to treatment - Part 1. Radiol Bras. 2017; 50:38-47.

4. Ramalho M, Matos AP, AlObaidy M, et al. Magnetic resonance imaging of the cirrhotic liver: diagnosis of hepatocellular carcinoma 


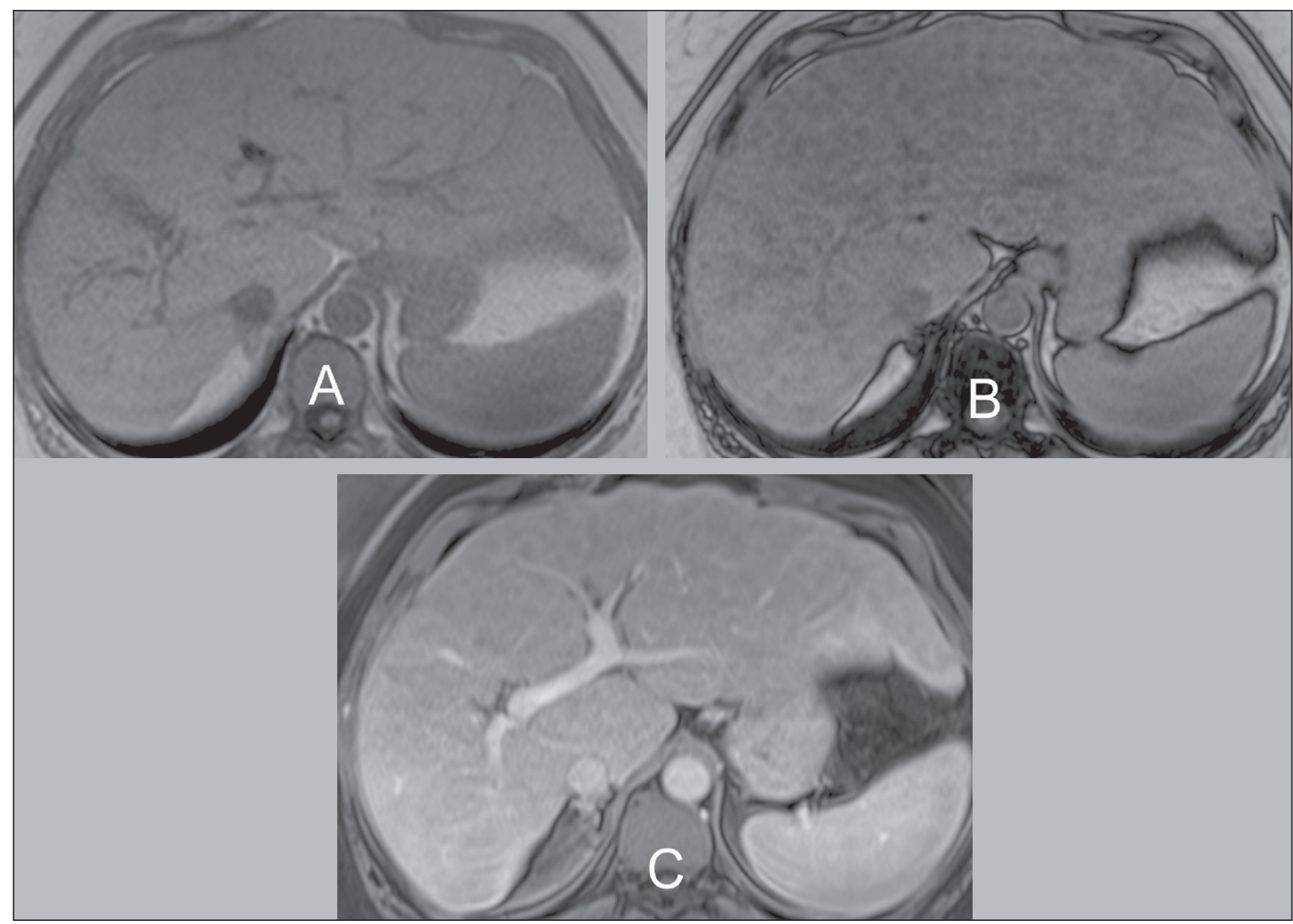

Figure 7. Fat-containing regenerative nodules. A: Axial T1-weighted image shows a cirrhotic liver, with volume increase of the caudate and left lobes, with nodular contour and heterogeneous signal intensity. B: Axial T1-weighted out-of-phase image demonstrates multiple diffuse small nodules with signal loss, characteristic of steatotic regenerative nodules. C: Axial T1-weighted image with fat saturation venous phase image shows nodule enhancement to the same degree as the adjacent liver.

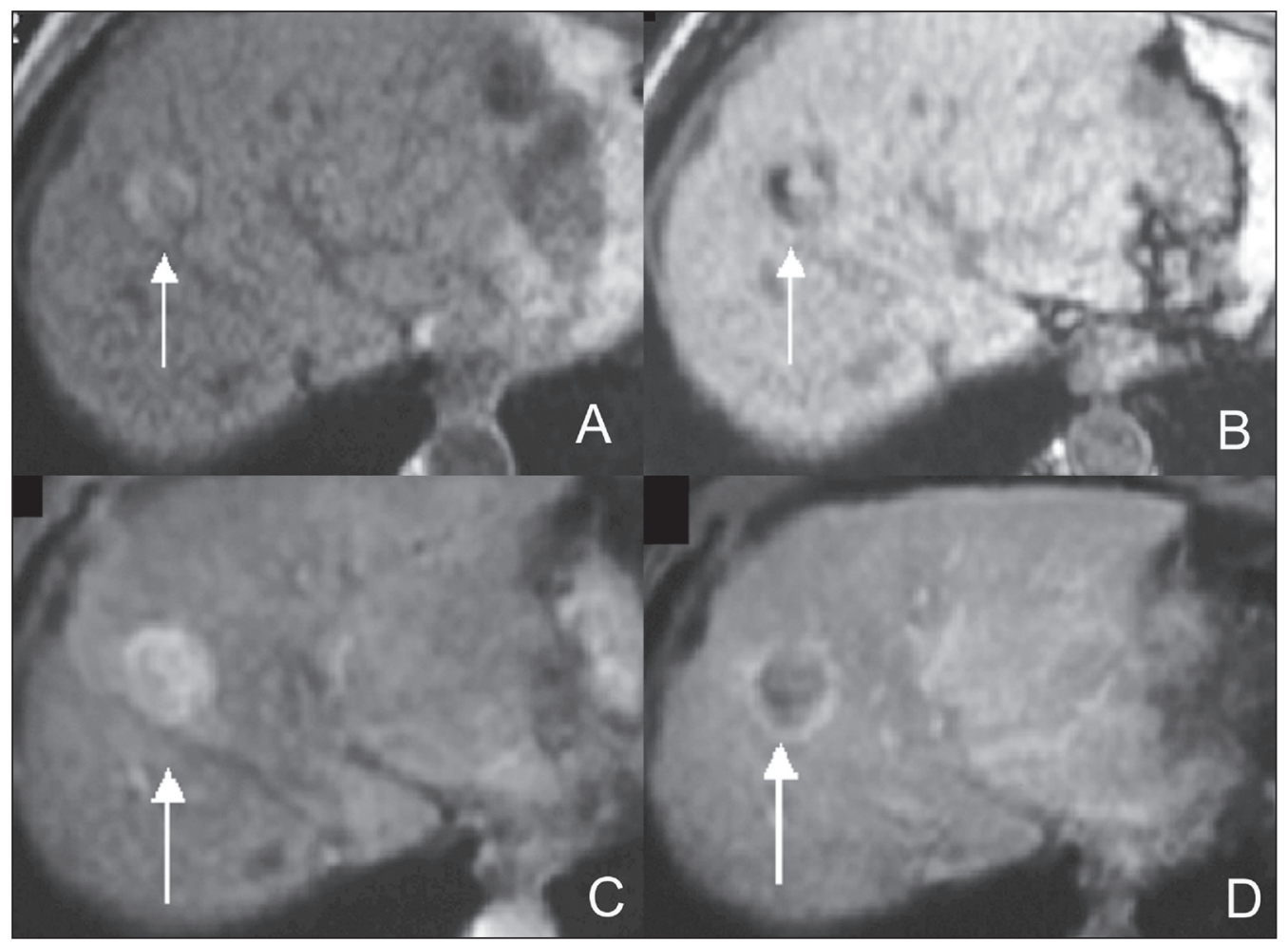

Figure 8. Hepatocellular carcinoma with focal fat deposition. A: Axial in-phase T1-weighted GRE sequence shows a heterogeneously hyperintense lesion (arrow). B: Axial out-of-phase T1-weighted GRE sequence shows focal areas of signal loss within the lesion (arrow). C,D: On axial T1-weighted image with fat saturation arterial phase image (C), the lesion demonstrates strong homogeneous enhancement with washout (D) and pseudocapsule enhancement (arrow). 
and evaluation of response to treatment - Part 2. Radiol Bras. 2017; 50:115-25.

5. Zurstrassen CE, Bitencourt AGV, Guimaraes MD, et al. Percutaneous stent placement for the treatment of malignant biliary obstruction: nitinol versus elgiloy stents. Radiol Bras. 2017;50:97-102.

6. Melo-Leite AF. The powerful "lens" of magnetic resonance imaging in the diagnosis of hepatic nodules in patients with cirrhosis: diagnosis of hepatocellular carcinoma without the need of histopathological confirmation - fact! Radiol Bras. 2017;50(1):vii-viii.

7. Cardarelli-Leite L, Fornazari VAV, Peres RR, et al. The value of percutaneous transhepatic treatment of biliary strictures following pediatric liver transplantation. Radiol Bras. 2017;50:308-13.

8. Candido PCM, Pereira IMF, Matos BA, et al. Giant pedunculated hemangioma of the liver. Radiol Bras. 2016;49:57-8.

9. Giardino A, Miller FH, Kalb B, et al. Hepatic epithelioid hemangioendothelioma: a report from three university centers. Radiol Bras. 2016;49:288-94.

10. Cruz JF, Cruz MAF, Machado Neto J, et al. Prevalence and sonographic changes compatible with fatty liver disease in patients referred for abdominal ultrasound examination in Aracaju, SE. Radiol Bras. 2016;49:1-5.
11. Bahirwani R, Reddy KR. Review article: the evaluation of solitary liver masses. Aliment Pharmacol Ther. 2008;28:953-65.

12. Basaran C, Karcaaltincaba M, Akata D, et al. Fat-containing lesions of the liver: cross-sectional imaging findings with emphasis on MRI. AJR Am J Roentgenol. 2005;184:1103-10.

13. Petrolla AA, Xin W. Hepatic angiomyolipoma. Arch Pathol Lab Med. 2008;132:1679-82.

14. Prasad SR, Wang H, Rosas H, et al. Fat-containing lesions of the liver: radiologic-pathologic correlation. Radiographics. 2005;25:321-31.

15. Gibo M, Murata S, Kuroki S. Pericaval fat collection mimicking an intracaval lesion on CT in patients with chronic liver disease. Abdom Imaging. 2001;26:492-5.

16. Quinn AM, Guzman-Hartman G. Pseudolipoma of Glisson capsule. Arch Pathol Lab Med. 2003;127:503-4.

17. Seale MK, Catalano OA, Saini S, et al. Hepatobiliary-specific MR contrast agents: role in imaging the liver and biliary tree. Radiographics. 2009;29:1725-48.

18. Parente DB, Perez RM, Eiras-Araujo A, et al. MR imaging of hypervascular lesions in the cirrhotic liver: a diagnostic dilemma. Radiographics. 2012;32:767-87. 